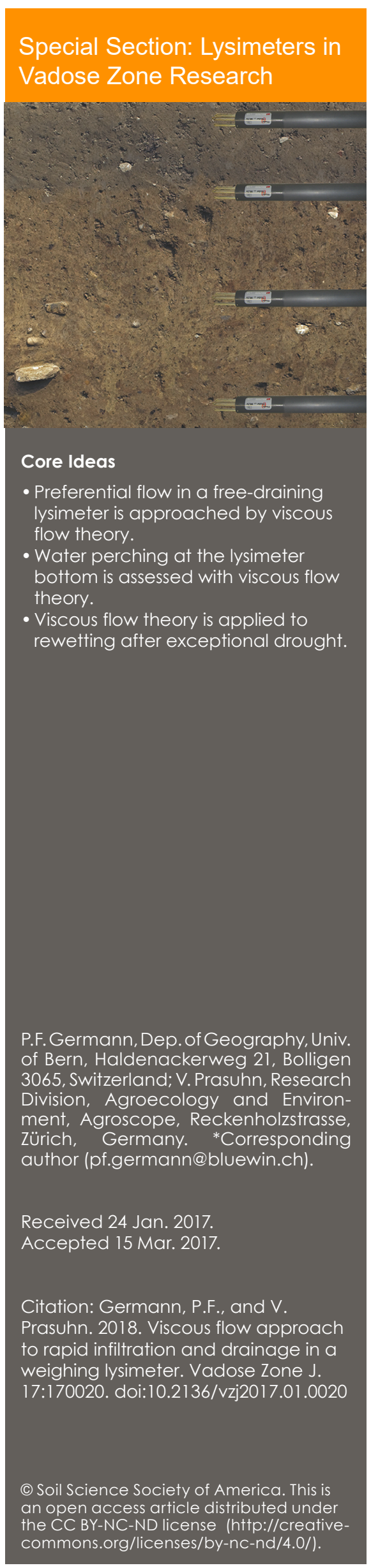

\title{
Viscous Flow Approach to Rapid Infiltration and Drainage in a Weighing Lysimeter
}

\section{Peter F. Germann* and Volker Prasuhn}

Rapid infiltration and drainage in a free-draining weighing lysimeter are assessed with a viscous flow approach that is based on the concept of moving water films. The two parameters film thickness and specific contact area of the film per unit volume of the permeable medium together with the rate and duration of water input suffice to quantify viscous flow at the Darcy scale. The two parameters are deducible from wetting front velocities and water content variations during the passing of the film. Temporarily perching water tables at lysimeter bottoms are considered artifacts of the lysimeter method that may severely alter the biogeochemistry of the effluent. The viscous flow approach assesses the duration of water perching from drainage flow interpretation. Perching in the sense of viscous flow occurred at most $10 \%$ of the time during drainage flow. Drainage ceased completely during a 6-mo period that yielded only $46 \%$ of rainfall compared with the 30 -yr average. During rewetting of the lysimeter soil, viscous flow applied to infiltrations of nine precipitation episodes, showing successive penetrations of wetting fronts shortly before the onset of drainage.

Abbreviations: FDR, frequency domain reflectometry; WCW, water content wave.

Lysimeters (Greek: effluent meters) control the enclosed soil's boundaries with respect to solute and water fluxes. Weighing lysimeters allow additionally for closing the water balance, resulting in the quantification of evapotranspiration, e.g., Gebler et al. (2015). Instead of weighing, al Hagrey et al. (1999) used ground-penetrating radar to record the temporal variations in water content in an entire sand-tank lysimeter that was $2 \mathrm{~m}$ deep and carried an approximate volume of $50 \mathrm{~m}^{3}$. Other types of equipment can support detailed investigations of flow and transport at preset time and space scales. Schuhmann et al. (2016), for instance, investigated the fate of the herbicide chloridazon [5-amino4-chloro-2-phenyl-3 $2 \mathrm{H}$ )-pyridazinone] during its passing across lysimeters. This study dealt exclusively with freely draining lysimeters.

More than $130 \mathrm{yr}$ ago, Lawes et al. (1882) anticipated a rapid drainage response to precipitation in the lysimeters of the Rothamsted (UK) research station. They found that " $[t]$ he drainage water of a soil may thus be of two kinds (1) of rainwater that has passed with but little change in composition down the open channels of the soil; or (2) of the water discharged from the pores of a saturated soil. The latter water, the true drainage of the soil, will itself escape to a greater or lesser extent through the channels already mentioned." Likewise, Germann (1986) analyzed 389 drainage responses to precipitation in the lysimeters of the North Appalachian Experimental Watershed, Coshocton, OH (Harrold and Dreibelbis, 1958; Kelley et al., 1975). He concluded that daily rainfall of $10 \mathrm{~mm}$ was sufficient to trigger drainage at the 2.4-m depth within 1 to $2 \mathrm{~d}$ after water input if the average water content exceeded $0.3 \mathrm{~m}^{3} \mathrm{~m}^{-3}$ in the range from the surface to the $1-\mathrm{m}$ depth.

Rapid flow is also of concern for groundwater quality. For instance, the depth to groundwater is typically between 10 and $50 \mathrm{~m}$ in the chalk formations of South Hampshire, UK. The ${ }^{18} \mathrm{O} /{ }^{16} \mathrm{O}$-ratio studies of pore waters in the 1970 s revealed a downward velocity of about $1 \mathrm{~m} \mathrm{yr}^{-1}$ of the water balances' annual surplus (Atkinson and Smith, 1974). Thus, 
the expected pore-water's residence time is in the order of decades. However, local groundwater users occasionally complained about bad odors in the water supply system within weeks following liquid manure applications, and Reeves (1979) estimated wetting front velocities between 1 and $100 \mathrm{~m} \mathrm{~d}^{-1}$. He suggested mechanisms of rapid flow and transport across chalk formations similar to the dual-flow proposition of Lawes et al. (1882) for soil but over depths outpacing by far the typical soil and lysimeter profiles. Thus, modern weighing lysimeters also serve as analogs for the rapid response of drainage and groundwater tables to precipitation and other water inputs.

There are mainly three categories of rapid drainage responses to precipitation, also referred to as preferential flow, as Jarvis et al. (2016) most recently postulated: finger flow (e.g., Selker et al., 1992), macropore flow (e.g., Beven and Germann, 1982), and nonequilibrium flow (e.g., Šimůnek and van Genuchten, 2008). Viscous flow, as discussed here, applies to all three categories: to finger flow according to Hincapié and Germann (2010), to rapid infiltration in a structured forest soil (e.g., Germann and Karlen, 2016) as well as to flow in fissured limestone (e.g. Germann, 2014), and to nonequilibrium flow in homogeneous sand (Germann and al Hagrey, 2008). Regardless of the cause of preferential flow, viscous flow applies to all three categories. Therefore, media carrying viscous flow are called permeable in contrast to the subunit of porous media that carries dominantly Richards (1931) capillary flow.

Confined lysimeters serve as analogs of similar but unconfined soils. However, the bottoms of free-draining lysimeters may interfere with drainage, thus limiting the analog concept. Prolonged water saturation in the capillary fringe may lead to anoxic conditions that, among other chemical artifacts ascribed to lysimeter studies, are particularly crucial in $\mathrm{NO}_{3}-\mathrm{NO}_{2}$ biochemistry. For instance, Hagenau et al. (2015) detected differences between water regimes determined in lysimeters and nearby soils, whereas Meissner et al. (2010) found no significant differences in the water regimes and effluent quality between a free-draining lysimeter and the adjacent soil. However, the unconfined soil of Meissner et al. (2010) was sitting on groundwater whose level temporarily varied around the $1-\mathrm{m}$ depth. They adjusted level variations in the unhampered neighboring soil experimentally to the confined lysimeter soil. They did not really solve the problem of the capillary fringe in free-draining lysimeters but simply circumvented it. Abdou and Flury (2004) clearly demonstrated the capillary fringe effect in free-draining lysimeters by simulation with the CHAIN_2D code that is based on the Richards (1931) equation. They admitted that "[i]n the presence of preferential flow, however, free-drainage lysimeters underestimate the amount of pesticide leached. Lysimeter results in this case (vertically structured soils or preferential flow) need to be used with caution." The conclusion of Abdou and Flury (2004) justifies the focus on preferential drainage with respect to the capillary fringe.
We used 12 examples of preferential infiltration and drainage to assess the viscous-flow theory. We then assessed the significance of water perching during drainage in view of viscous flow. Finally, nine precipitation episodes shortly before drainage restarted after a prolonged drought assessed the applicability of the viscous-flow approach to preferential infiltration and drainage.

\section{Theory}

Viscous flow is based on moving water films. They are exclusively gravity driven against the resistance of viscosity. The thickness $F(\mu \mathrm{m})$ and the dominantly vertical specific contact area $L$ $\left(\mathrm{m}^{2} \mathrm{~m}^{-3}\right)$ per unit volume of the permeable medium completely characterize a film. Capillarity may suck water from the film into finer pores, whereby capillary abstraction is treated summarily as a component in the water balance. The following presents only the viscous-flow relationships that are relevant to this discussion. See Germann and Karlen (2016) and Germann (2014) for the development of the viscous-flow theory and its application to infiltration and drainage.

Given is a rectangular pulse of water input to the surface of the permeable medium with a constant volume flux density $q_{\mathrm{S}}\left(\mathrm{m} \mathrm{s}^{-1}\right)$ that begins and ends at times $T_{\mathrm{B}}(\mathrm{s})$ and $T_{\mathrm{E}}(\mathrm{s})$. The pulse initiates a water content wave WCW whose evolution in a permeable medium is now pursued as mobile water content $w(z, t)\left(\mathrm{m}^{3} \mathrm{~m}^{-3}\right)$, where $z(\mathrm{~m})$ is depth positive downward from the surface and $t(\mathrm{~s})$ represents time. The following assumes no water abstraction from the WCW due to capillarity, thus the total volume of the WCW $\left(V_{\mathrm{WCW}}, \mathrm{m}\right)$ remains at

$V_{\mathrm{WCW}}=q_{\mathrm{S}}\left(T_{\mathrm{E}}-T_{\mathrm{B}}\right)$

The assumption is relaxed below when the approach is applied to data. The WCW starts moving at the soil surface at $T_{\mathrm{B}}$, and its mobile water content, i.e., the wave's amplitude, amounts to

$w(z, t)=L(z, t) F$

In most instances, $w$ is greatly inferior to the total volumetric water content $\theta\left(\mathrm{m}^{3} \mathrm{~m}^{-3}\right)$. The volume flux density of the film $q(z, t)$ $\left(\mathrm{m} \mathrm{s}^{-1}\right)$ is

$q(z, t)=\frac{g}{3 \eta} L(z, t) F^{3}=w(z, t)^{3} \frac{g}{3 \eta L(z, t)^{2}}$

where $g=9.81 \mathrm{~m} \mathrm{~s}^{-2}$ and $\eta \approx 10^{-6} \mathrm{~m}^{2} \mathrm{~s}^{-1}$ represent acceleration due to gravity and kinematic viscosity, respectively. Equation [3] is referred to as the viscous-flow equation. The wetting front velocity of the film $v\left(\mathrm{~m} \mathrm{~s}^{-1}\right)$ follows from the water balance as

$v=\frac{q}{w}=\frac{g}{3 \eta} F^{2}$ 
At $T_{\mathrm{E}}$ (cessation of the input pulse), a draining front starts moving with the wave velocity

$c=\frac{\mathrm{d} q}{\mathrm{~d} w}=3 v$

Because $c=3 v$, the wetting front intercepts the draining front at time $T_{\mathrm{I}}(\mathrm{s})$ and depth $Z_{\mathrm{I}}(\mathrm{m})$ :

$T_{I}=\frac{1}{2}\left(3 T_{\mathrm{E}}-T_{\mathrm{B}}\right)$

and

$$
Z_{\mathrm{I}}=\frac{c}{2}\left(T_{\mathrm{E}}-T_{\mathrm{B}}\right)
$$

The positions of the wetting and draining fronts within $0 \leq z \leq$ $Z_{\mathrm{I}}$ as functions of time are

$z_{\mathrm{W}}(t)=v\left(t-T_{\mathrm{B}}\right)$

$z_{\mathrm{D}}(t)=c\left(t-T_{\mathrm{E}}\right)$

$t_{\mathrm{D}}(z)=T_{\mathrm{E}}+\frac{z}{c}$

After $T_{\mathrm{I}}$ and beyond $Z_{\mathrm{I}}$, the draining front vanishes and the temporal position of the wetting front is

$z_{\mathrm{W}}(t)=c\left(t-T_{E}\right)^{1 / 3}\left(\frac{T_{\mathrm{E}}-T_{\mathrm{B}}}{2}\right)^{2 / 3}$

while the arrival time of the wetting front at depths $z \geq$ $Z_{\mathrm{I}}$ is

$t_{\mathrm{W}}(z)=T_{\mathrm{E}}+4\left(\frac{z}{c}\right)^{3}\left(T_{\mathrm{E}}-T_{\mathrm{B}}\right)^{-2}$

Figure 1 illustrates the temporal positions of the wetting and draining fronts. The three lines constitute the characteristics (i.e., trajectories) of the WCW according to Lighthill and Witham (1955).

Volume flux densities and mobile water contents in the following four periods need consideration:

$T_{\mathrm{B}} \leq t \leq t_{\mathrm{W}}(z)$

$q(z, t)=0$ $w(z, t)=0$

$t_{\mathrm{W}}(z) \leq t \leq t_{\mathrm{D}}(z)$

$q(z, t)=q_{\mathrm{S}}$

$w(z, t)=w_{\mathrm{S}}$

where $w_{\mathrm{S}}\left(\mathrm{m}^{3} \mathrm{~m}^{-3}\right)$ is the mobile water content corresponding to the volume flux density $q_{S}$ because, at the surface of the permeable medium, both have spontaneously adjusted to the input pulse and the actual hydraulic conditions of the medium,

$t_{\mathrm{D}}(z) \leq t \leq T_{\mathrm{I}}$

$q(z, t)=q_{\mathrm{S}}\left[\frac{t_{\mathrm{D}}(z)-T_{\mathrm{E}}}{t-T_{\mathrm{E}}}\right]^{3 / 2}$

$w(z, t)=w_{\mathrm{S}}\left[\frac{t_{\mathrm{D}}(z)-T_{\mathrm{E}}}{t-T_{\mathrm{E}}}\right]^{1 / 2}$

$t \geq T_{\mathrm{I}}$

$q(z, t)=\frac{V_{\mathrm{WCW}}}{2}\left[t_{\mathrm{W}}(z)-T_{\mathrm{E}}\right]^{1 / 2}\left(t-T_{\mathrm{E}}\right)^{-3 / 2}$

$w(z, t)=\frac{3 V_{\mathrm{WCW}}}{2 z}\left[\frac{t_{\mathrm{W}}(z)-T_{\mathrm{E}}}{t-T_{\mathrm{E}}}\right]^{1 / 2}$

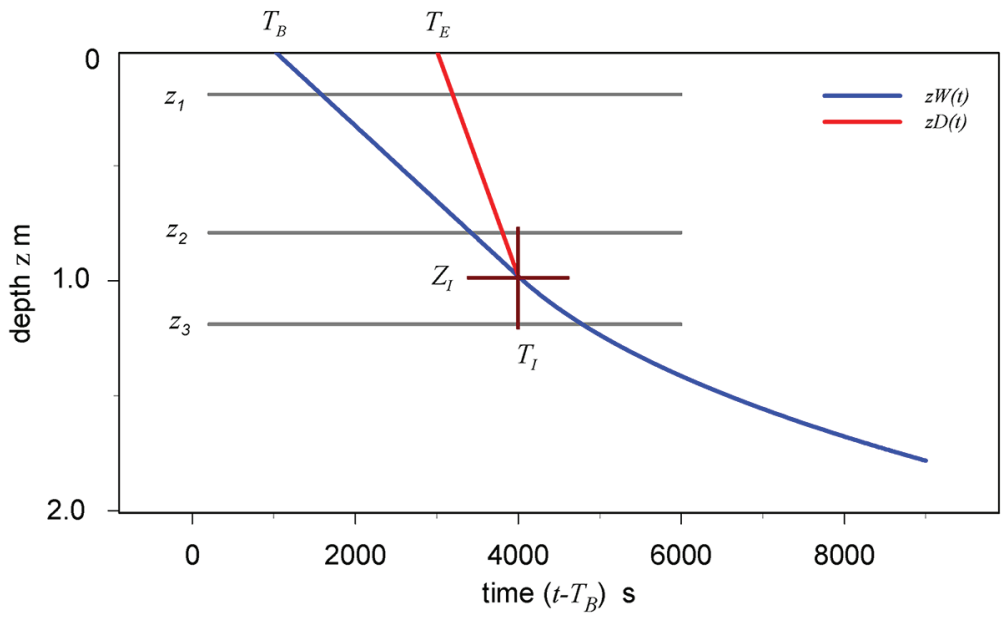

Fig. 1. Synthetic characteristics of a water content wave, WCW, with wetting front depth $z_{\mathrm{W}}(t)$ and draining front wave $z_{\mathrm{D}}(t)$, computed with the following parameters: beginning time $T_{\mathrm{B}}=1000 \mathrm{~s}$; ending time $T_{\mathrm{E}}=3000 \mathrm{~s}$; specific contact area $L$ $=2000 \mathrm{~m}^{2} \mathrm{~m}^{-3}$; and thickness $F=10^{-5} \mathrm{~m}$. The cross indicates where the wetting front intercepts the draining front at time $T_{\mathrm{I}}$ and depth $Z_{\mathrm{I}}$ equal to $4000 \mathrm{~s}$ and 0.98 $\mathrm{m}$, while the volume flux density $q_{\mathrm{S}}=6.6 \times 10^{-6} \mathrm{~m} \mathrm{~s}^{-1}$, mobile water content $w_{\mathrm{S}}=$ $0.02 \mathrm{~m}^{3} \mathrm{~m}^{-3}$, and the wetting front velocity of the film $v=3.3 \times 10^{-4} \mathrm{~m} \mathrm{~s}^{-1}$. The depths are $z_{1}=0.2 Z_{\mathrm{I}}, z_{2}=0.8 Z_{\mathrm{I}}$, and $z_{3}=1.2 Z_{\mathrm{I}}$. 
Figure 2 depicts the mobile water contents and related fluxes as functions of time at various depths.

The following assesses the forcing of preferential drainage that is either exclusively gravity driven in the sense of viscous flow as presented above or a pressure gradient is additionally involved. The assessment allows estimating the duration of perching in the sense of preferential flow. Hydraulic conductivity at saturation, $K_{\text {sat }}\left(\mathrm{m} \mathrm{s}^{-1}\right)$, is gravity-driven viscous flow when all pores are saturated, i.e., Darcy (1856) flow with unit hydraulic gradient (Germann and Karlen, 2016). Drainage flow decreases after the arrival of the draining front at the lysimeter's bottom, i.e., during $t$ $\geq t_{\mathrm{D}}(z)$ (Eq. [18] and [20]; Fig. 2). Perching increases the hydraulic gradient above unity between the water table and the lysimeter's bottom. Draining groundwater follows the rule of a draining linear reservoir, i.e.,

$$
q\left(z_{\mathrm{D}}, t\right)=q\left(z_{\mathrm{D}}, t_{\mathrm{D}}\right) \exp \left[-\lambda\left(t-t_{\mathrm{D}}\right)\right]
$$

where $\lambda\left(\mathrm{s}^{-1}\right)$ is the reservoir constant. Perching during preferential drainage occurs whenever the temporal derivative of Eq. [22] exceeds that of either Eq. [18] or Eq. [20], depending on either $Z_{\mathrm{L}}$ $<Z_{\mathrm{I}}$ or $Z_{\mathrm{L}}>Z_{\mathrm{I}}$ (Germann, 2014), where $Z_{\mathrm{L}}(\mathrm{m})$ is the depth of the lysimeter's drain flow collector, usually some kind of a spout.
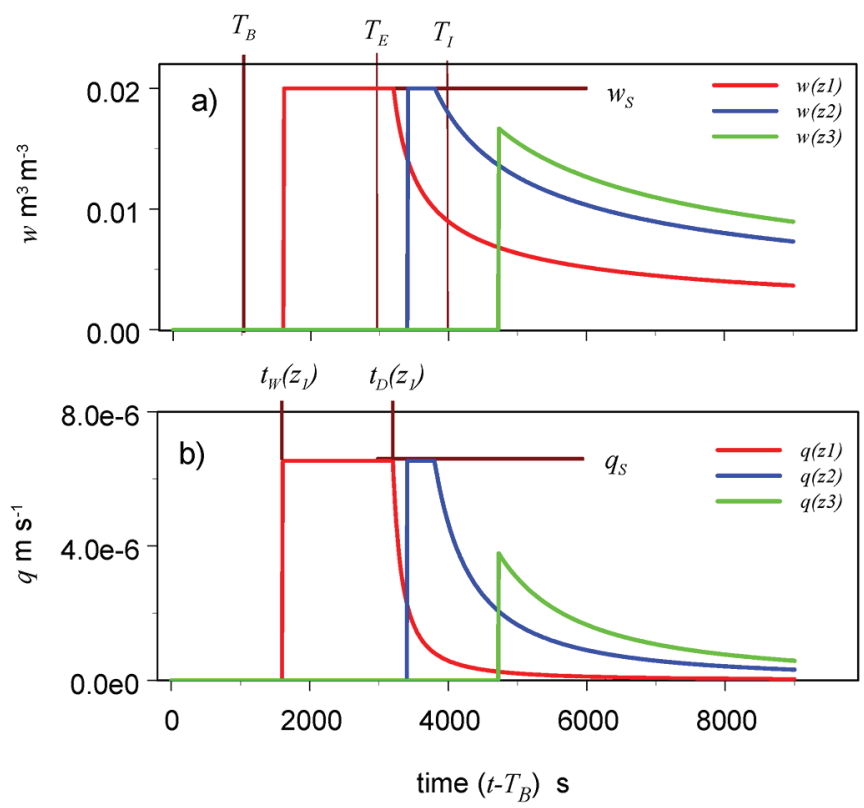

Fig. 2. Synthetic time series of (a) volumetric water contents $w\left(z_{1}\right)$, $w\left(z_{2}\right)$, and $w\left(z_{3}\right)$ and (b) volume flux densities $q\left(z_{1}\right), q\left(z_{2}\right)$, and $q\left(z_{3}\right)$ at the same depths $z_{1}$ to $z_{3}$ with the following parameters: beginning time $T_{\mathrm{B}}=1000 \mathrm{~s}$; ending time $T_{\mathrm{E}}=3000 \mathrm{~s}$; specific contact area $L=2000 \mathrm{~m}^{2} \mathrm{~m}^{-3}$; and thickness $F=10^{-5} \mathrm{~m}$. The cross indicates where the wetting front intercepts the draining front at time $T_{\mathrm{I}}$ and depth $Z_{\mathrm{I}}$ of $4000 \mathrm{~s}$ and $0.98 \mathrm{~m}$, while the volume flux density $q_{\mathrm{S}}=6.6 \times 10^{-6} \mathrm{~m} \mathrm{~s}^{-1}$, mobile water content $w_{\mathrm{S}}=0.02 \mathrm{~m}^{3} \mathrm{~m}^{-3}$, and the wetting front velocity of the film $v=3.3 \times 10^{-4} \mathrm{~m} \mathrm{~s}^{-1}$. The depths are $z_{1}=0.2 Z_{\mathrm{I}}, z_{2}=0.8 Z_{\mathrm{I}}$, and $z_{3}=1.2 Z_{\mathrm{I}}$.

\section{Soil and Methods}

The lysimeter facility of Agroscope includes 72 monoliths; all of them have a surface area of $1 \mathrm{~m}^{2}$ and are $1.5 \mathrm{~m}$ deep. The data of Lysimeter 3 were further analyzed in this study. The soil monolith is a sandy-loamy Cambisol that originally sat on a ground moraine. Figure 3 a shows the soil profile and Table 1 summarizes the soil properties.

Construction of the monolith was done by hydraulically pressing the vessel's mantle $1.5 \mathrm{~m}$ deep into the ground. The soil surface was capped with a steel plate before turning the vessel upside down. The monolith's bottom at the 1.35 -m depth was cleared and repacked to the $1.5-\mathrm{m}$ depth with three layers of a sand-gravel mixture consisting of cleansed quartz in the particle size range from 0.1 to $5.6 \mathrm{~mm}$. The bottom was capped with a steel plate including the drain. The monolith was turned again and the steel plate on top was removed after heaving the lysimeter onto the trusses of the electronic balance (Prasuhn et al., 2016). Temperature and soil-water relationships are recorded with thermistors as well as with frequency domain reflectometry (FDR) probes (ThetaProbe ML2x, Delta-T Devices), equilibrium tensiometers (EQ15, Ecomatic), and pressure transducer tensiometers (Tensio 150, UGT) at depths of 0.1, 0.3, 0.6 , and $0.9 \mathrm{~m}$. A tipping-bucket device measures drainage flow by recording the time whenever $100 \mathrm{~mL}$ (equivalent of $0.1 \mathrm{~mm}$ ) are collected. Figures $3 \mathrm{a}$ and $3 \mathrm{~b}$ illustrate the soil profile, instrumentation, and general setting. For details, see Meissner et al. (2008), Prasuhn et al. (2009), and Sturzenegger (2010). The meteorological data were recorded at 10 -min time steps at a meteorological station within $20 \mathrm{~m}$ of the lysimeter facility. The Federal Office of Meteorology and Climatology, MeteoSwiss, maintains the station.

\section{Data Selection}

The time series selected for this study starts on 1 Oct. 2014 at 0:00 h, i.e., on Day 1, and ends on 29 Apr. 2016, thus covering 577 d, equivalent to 83,088 10-min periods. Figure 4 depicts the data records of the entire period that includes the meteorological drought of the second half of 2015. On a monthly base, the meteorological drought lasted from 1 July to 31 Dec. 2015, i.e., from Day 274 to Day 458. Table 2 presents the statistical background showing that only $46 \%$ of precipitation was recorded during that period compared with the monthly averages of the 30-yr period from 1981 to 2010 . The drought was exceptional for the Atlantic climate encountered in the Swiss lowlands, but it includes rewetting of the soil. The shortage of precipitation in combination with evapotranspiration brought drainage to a complete halt. The hydrological drought, as indicated in Fig. 4, marks the absence of drainage. It lasted from Days 270 to 467 (days counted from 1 Oct. 2014). Twelve infiltration and drainage events were selected for detailed viscous-flow investigations. Selection criteria were complete data sets of precipitation, wetting front advancements as indicated by increasing water contents at all four FDR depths, and drainage. The 11 episodes for studying perching were selected such that Eq. [22] applied. The even distribution 

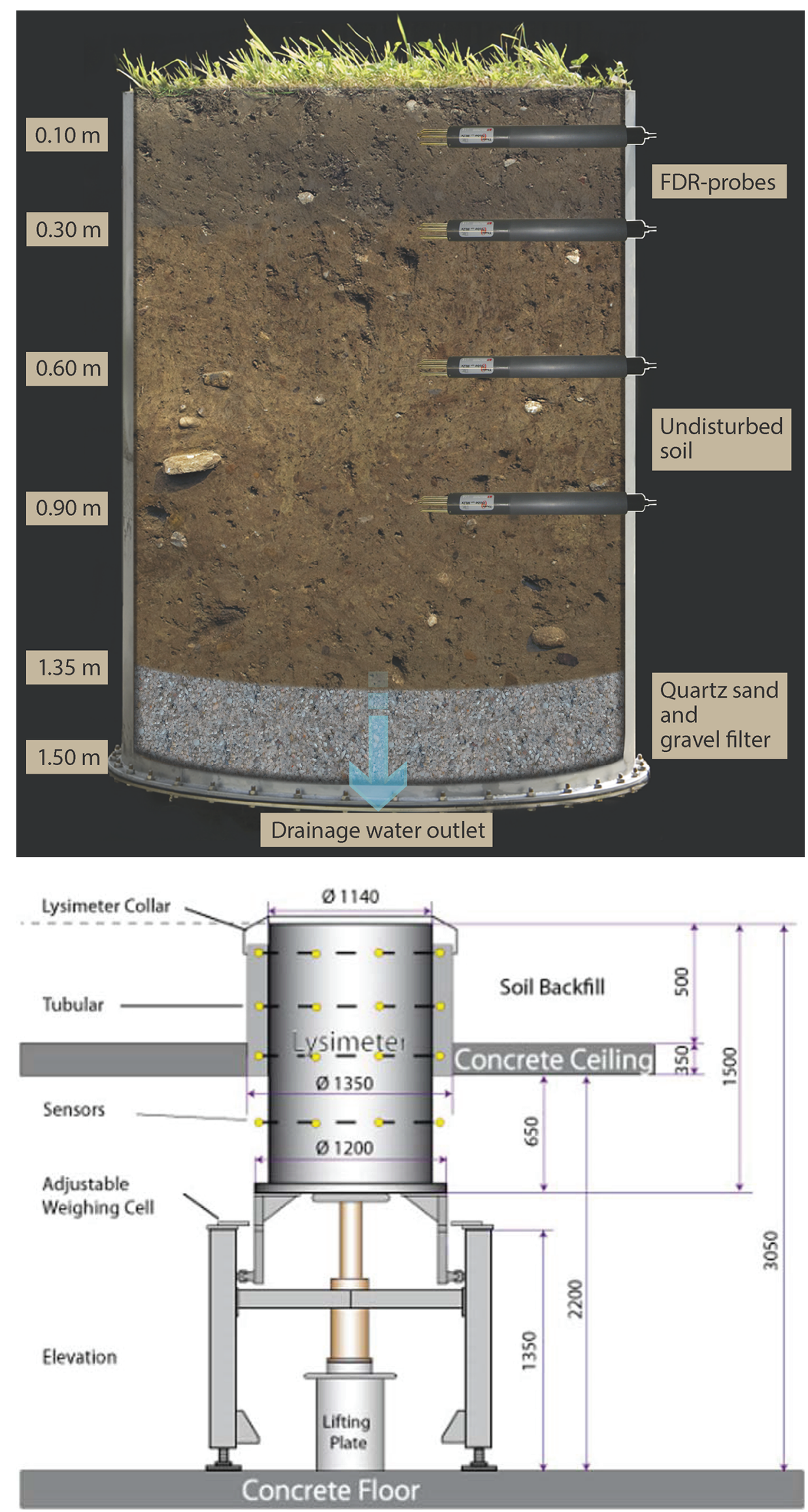

Fig. 3. Freely draining weighing lysimeter: soil profile with frequency domain reflectometry (FDR) probes at depths $0.1,0.3$, 0.6 , and $0.9 \mathrm{~m}$, a quartz sand and gravel filter between the 1.35- and 1.5-m depths, and a drainage outlet through the bottom (top, Agroscope, Ursus Kaufmann), and scheme of the weighing lysimeter (bottom, lengths in millimeters). 
Table 1. Properties of the soil used in this study.

\begin{tabular}{|c|c|c|c|c|c|c|c|c|}
\hline \multirow[b]{2}{*}{ Horizon } & \multirow[b]{2}{*}{ Depth } & \multicolumn{3}{|c|}{ Texture } & \multirow[b]{2}{*}{ Organic matter } & \multirow[b]{2}{*}{ Bulk density } & \multirow[b]{2}{*}{ Porosity } & \multirow{2}{*}{$\begin{array}{l}\mathrm{pH} \\
\left(\mathrm{CaCl}_{2}\right)\end{array}$} \\
\hline & & Sand & Silt & Clay & & & & \\
\hline & $\mathrm{m}$ & - & 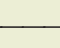 & $\mathrm{N} / \mathrm{w})$ & - & $\mathrm{kg} \mathrm{m}^{-3}$ & $\%(\mathrm{v} / \mathrm{v})$ & \\
\hline Ahp & $0-0.25$ & 51 & 32 & 17 & 1.7 & 1450 & 44 & 6.3 \\
\hline $\mathrm{Bcn}$ & $0.25-0.65$ & 53 & 27 & 20 & 0.3 & 1560 & 41 & 5.8 \\
\hline$B(g) t$ & $0.65-1.10$ & 58 & 24 & 18 & 0.2 & 1600 & 42 & 5.7 \\
\hline $\mathrm{Bg}(\mathrm{t})$ & $1.10-1.35$ & 57 & 27 & 16 & 0.1 & 1600 & 40 & 5.9 \\
\hline
\end{tabular}

of the two subsets within the time span from 1 Oct. 2014 to 29 Apr. 2016 was an additional selection criterion.

\section{Data Interpretation}

\section{Parameter Estimation of Preferential} Infiltration and Drainage

A constant wetting-front velocity $v$ prior to front interception at time $T_{\mathrm{I}}$ (Eq. [4] and [6]; Fig. 1) is a salient feature of viscous

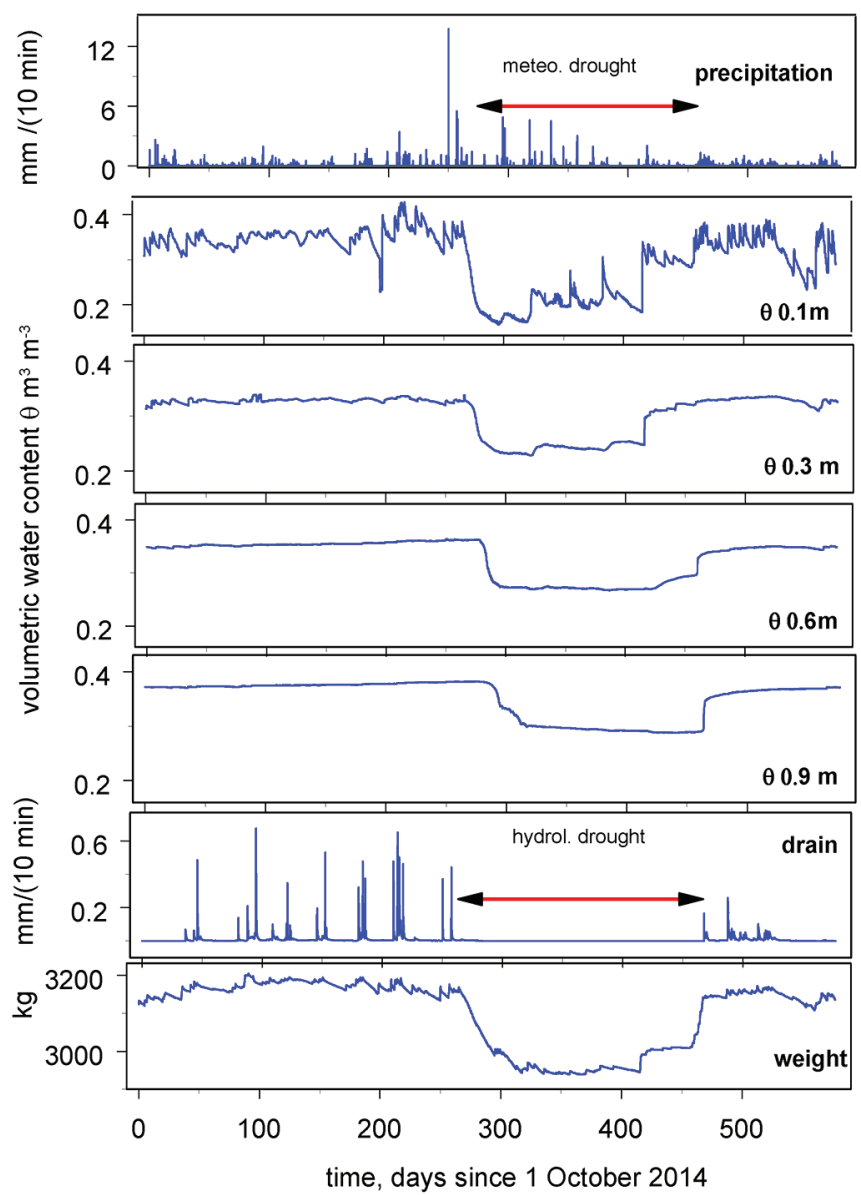

Fig. 4. Data used in the study: precipitation from the MeteoSwiss station; volumetric water contents recorded with frequency domain reflectometer probes at depths of $0.1,0.3,0.6$, and $0.9 \mathrm{~m}$; drainage collected at the $1.5-\mathrm{m}$ depth with a tipping bucket device; and total weight of the lysimeter. Indicated are the meteorological and hydrological droughts lasting from Days 274 to 458 and from Days 270 to 467 , respectively. flow. Ideally, if there is a complete WCW according to Eq. [1-21] from $T_{\mathrm{B}}$ to the increase in drainage flow at the $1.5-\mathrm{m}$ depth at $t_{\mathrm{W}}(1.5 \mathrm{~m})$, then constant $v$ is expected that is deducible from the arrival times $t_{\mathrm{W}}\left(z_{j}\right)$ of the wetting front at the various instrument depths between the surface and the drainage level. The arrival time $t_{\mathrm{W}}\left(z_{j}\right)$ of the wetting front at the depth $z_{j}$ of the $j$ th FDR probe follows from the significant increase in $\theta\left(z_{j}, t\right)$. Figure 5 illustrates the progression of the WCW that was released from the storm during Day 511. Table 3 lists $t_{\mathrm{W}}\left(z_{j}\right)$ at the instrument depths of $z_{j}=0.1,0.3,0.6,0.9$, and $1.5 \mathrm{~m}$. The first derivative $\mathrm{d} z / \mathrm{d} t_{\mathrm{W}}(z)$ of the linear regression of $z$ vs. $t_{\mathrm{W}}(z)$ yields $v=2.7 \times 10^{-5} \mathrm{~m} \mathrm{~s}^{-1}$ with the coefficient of determination $r^{2}=0.95$. Figure 6 illustrates $z_{\mathrm{W}}(t)$ and the corresponding linear regression.

Table 2. Monthly precipitation: Amount during investigated period compared with 30 -yr averages. Data in bold are the months with distinct precipitation deficits that define a meteorological drought.

\begin{tabular}{|c|c|c|c|c|c|}
\hline \multirow[b]{2}{*}{ Year } & \multirow[b]{2}{*}{ Month } & \multicolumn{4}{|c|}{ Precipitation } \\
\hline & & $\begin{array}{l}\text { Mean } \\
1981-2010\end{array}$ & Actual & Difference & \multirow{2}{*}{$\begin{array}{l}\text { Proportion } \\
\text { of mean } \\
\%\end{array}$} \\
\hline & & \multicolumn{3}{|c|}{$-\mathrm{mm}$} & \\
\hline \multirow[t]{3}{*}{2014} & Oct. & 83 & 81 & -2 & 96 \\
\hline & Nov. & 79 & 86 & +7 & 108 \\
\hline & Dec. & 79 & 57 & -22 & 71 \\
\hline \multirow[t]{12}{*}{2015} & Jan. & 61 & 86 & +25 & 139 \\
\hline & Feb. & 59 & 33 & -26 & 55 \\
\hline & Mar. & 75 & 71 & -4 & 94 \\
\hline & Apr. & 79 & 160 & +81 & 201 \\
\hline & May & 114 & 111 & -3 & 96 \\
\hline & June & 116 & 119 & +3 & 102 \\
\hline & July & 112 & 44 & -68 & 39 \\
\hline & Aug. & 108 & 75 & -33 & 69 \\
\hline & Sept. & 90 & 23 & -67 & 25 \\
\hline & Oct. & 83 & 39 & -44 & 46 \\
\hline & Nov. & 79 & 58 & -21 & 73 \\
\hline & Dec. & 79 & 12 & -67 & 15 \\
\hline \multirow[t]{4}{*}{2016} & Jan. & 61 & 164 & +103 & 265 \\
\hline & Feb. & 59 & 78 & +19 & 130 \\
\hline & Mar. & 75 & 26 & -49 & 34 \\
\hline & Apr. & 79 & 102 & +23 & 128 \\
\hline \multicolumn{2}{|c|}{ July-Dec. 2015} & 551 & 251 & -300 & 46 \\
\hline
\end{tabular}




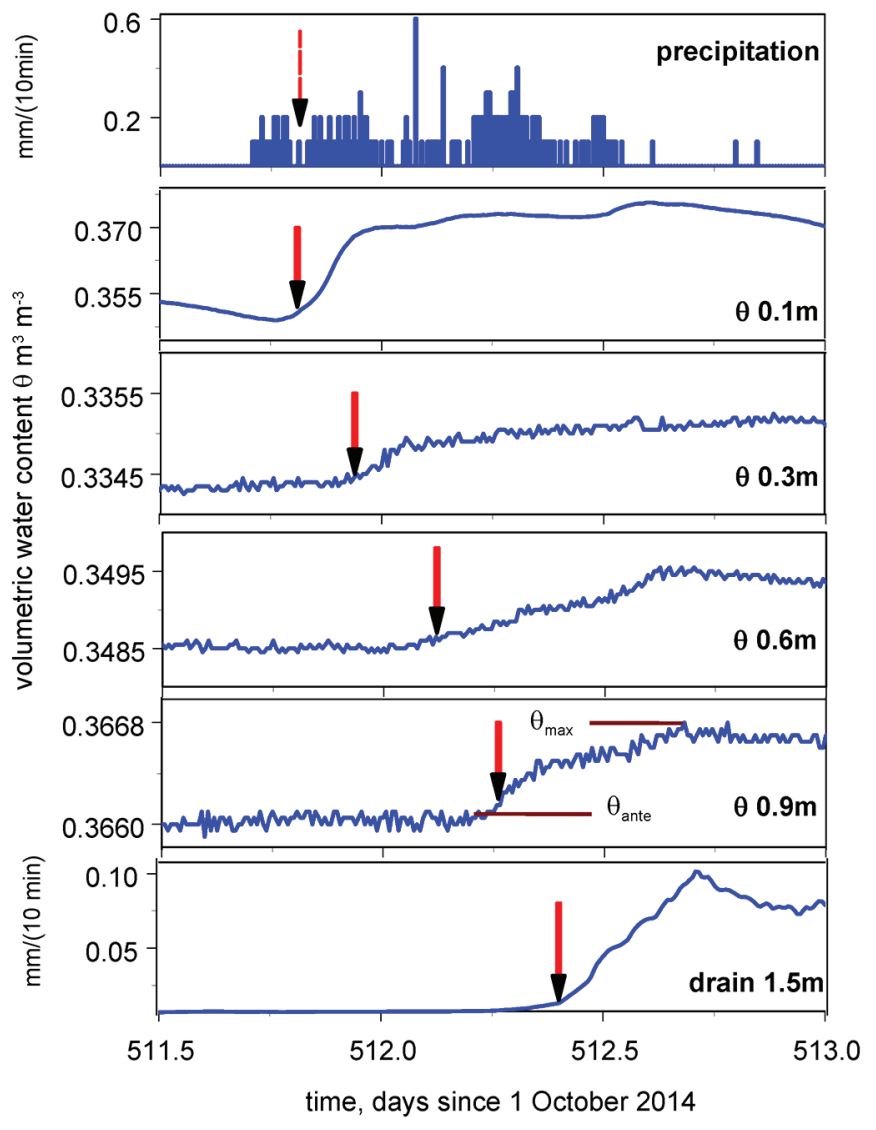

Fig. 5. Progression of the water content wave (WCW) at Day 511. Solid arrows indicate the arrival time $t_{\mathrm{W}}\left(z_{j}\right)$ of the wetting front at the respective depths $z_{j}$. By back-calculation, the dashed arrow shows the presumed beginning time $T_{\mathrm{B}}$ of the pulse that initiated the WCW; $\theta_{\text {ante }}$ and $\theta_{\max }$ at the $0.9-\mathrm{m}$ depth indicate volumetric water contents prior to and after the passing of the WCW. The scales of the panels vary for better illustration of the front arrival.

The same procedure was applied to 11 additional preferential flow episodes whose results are listed in Table 4 . The film thicknesses $F$ follow from Eq. [4]. The specific contact areas $L_{0.9}$ at the $0.9-\mathrm{m}$ depth were estimated with Eq. [2], where a WCW's amplitude is $w(0.9)=\left(\theta_{\max }-\theta_{\text {ante }}\right)$, i.e., the difference between the maximum and antecedent volumetric water contents during and prior to the passing of the WCW at $z=0.9 \mathrm{~m}$ (see Fig. 5). The application of Eq. [3] to the WCW passing the 0.9-m depth yields the rate of preferential flow $q_{0.9}$.

\section{Perching at the Lysimeter Bottom}

Temporary perching at the lysimeter bottom is assessed with Eq. [22], which is applied to the early section of decreasing drainage flow, while Eq. [18] or [20] is applied to its later section. Two pairs of data points are required in each section to estimate in Eq. [18] or [20] and [22]: the parameters $\left[t_{\mathrm{D}}(z)-T_{\mathrm{E}}\right]$ and $T_{\mathrm{E}}$ on the one hand and $\lambda$ on the other hand. Optimization is by gradually moving the presumed point of crossing over from the linear-reservoir to the viscous-flow regime, while the respective coefficients of determination indicate the goodness of fit. Figure 7 illustrates the procedure
Table 3. Arrival times $t_{\mathrm{W}}(z)$ of the wetting fronts at the depths of the frequency domain reflectometry probes and at the lysimeter bottom.

\begin{tabular}{|c|c|}
\hline Depth $z$ & Arrival time $t_{\mathrm{W}}(z)$ \\
\hline $\mathrm{m}$ & $\mathrm{d}$ \\
\hline 0 & $511.77 \dagger$ \\
\hline 0.1 & 511.81 \\
\hline 0.3 & 511.96 \\
\hline 0.6 & 512.14 \\
\hline 0.9 & 512.20 \\
\hline 1.5 & 512.40 \\
\hline \multicolumn{2}{|c|}{$\begin{array}{l}\text { † The water content wave's apparent release time at the surface, } z=0 \text {, was } \\
\text { back-calculated using the wetting front velocity } v \text { resulting from the linear } \\
\text { regression, Fig. } 6 \text {. }\end{array}$} \\
\hline
\end{tabular}

during the drainage recession at Day 80 , while Table 5 compiles 11 episodes with perching water tables. The parameter $q_{\text {visc,max }}$ represents the maximum of the volume flux densities of the viscous flow regime, i.e., the volume flux density at the point of crossing over. In Table 5, the approximate range of $\mathrm{q}_{\mathrm{visc} \text { max }}$ is between $3.8 \times 10^{-8}$ and $3.9 \times 10^{-7} \mathrm{~m} \mathrm{~s}^{-1}$, while its median is at $8.7 \times 10^{-8} \mathrm{~m} \mathrm{~s}^{-1}$. The duration of perching in each episode is the period when $q_{\text {drain }}>$ $q_{\text {visc,max }}$. Perching during the 11 episodes lasted from $1 \mathrm{~h} 40 \mathrm{~min}$ (Day 486) to $13 \mathrm{~h} 40 \mathrm{~min}$ (Day 179).

The significance of perching for the entire period of $577 \mathrm{~d}$ of investigation is assessed by the share of 10 -min periods with rates of drainage flow exceeding a threshold of presumed perching divided by the number of 48,690 such periods that recorded drainage at all. Table 6 compiles the shares of periods showing presumed perching with respect to various thresholds that represent the range listed in Table 5. For instance, the limit of $q_{\text {visc, } \max }=2 \times 10^{-7} \mathrm{~m} \mathrm{~s}^{-1}$ was exceeded during a total of 77110 -min periods, i.e., during 0.0158 of the entire period when drainage occurred. Based on the two drainage regimes, linear-reservoir flow vs. viscous flow, the duration of water saturation at the lysimeter bottom during individual episodes as well as during the entire period of investigation is considered insignificant with respect to the lysimeter's impact on the biogeochemistry of the effluent.

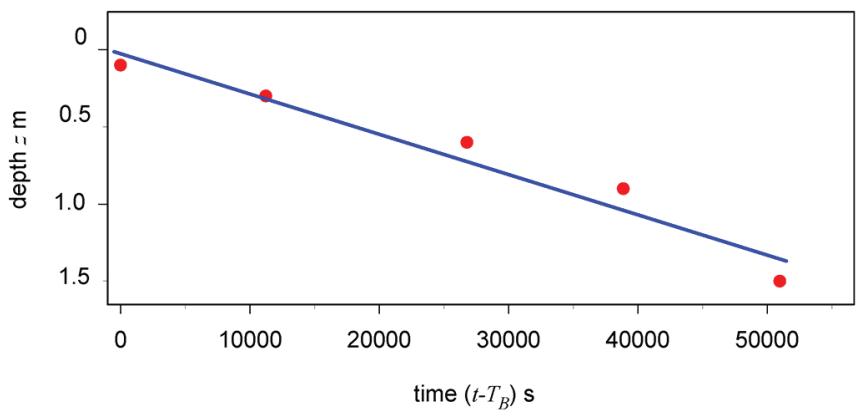

Fig. 6. Linear regression of instrument depths $z$ vs. arrival times $t_{\mathrm{W}}(z)$ of the wetting fronts. The slope of the regression equals the average wetting front velocity $v=\mathrm{d} z / \mathrm{d} t=2.7 \times 10^{-5} \mathrm{~m} \mathrm{~s}^{-1}$, and $r^{2}=0.95$. The arrival times $t_{\mathrm{W}}\left(z_{j}\right)$ are shown as arrows in Fig. 5 . 
Table 4. Wetting front velocities $v$, the coefficient of determination $r^{2}$ of the linear regression of depth vs. arrival time of the wetting front, the film thickness $F_{0.9}$, specific contact area $L_{0.9}$, and rate of viscous flow $q_{0.9}$ at the 0.9 -m depth, the maximum rate of drainage flow, $q_{\mathrm{d} \text {, max }}$, and ratio $q_{0.9} / q_{\mathrm{d}, \max }$.

\begin{tabular}{|c|c|c|c|c|c|c|c|}
\hline Dayt & $v$ & $r_{\mathrm{v}}^{2}$ & $F_{0.9}$ & $L_{0.9}$ & $q_{0.9}$ & $q_{\mathrm{d}, \max }$ & $q_{0.9} / q_{\mathrm{d}, \max }$ \\
\hline & $\times 10^{-6} \mathrm{~m} \mathrm{~s}^{-1}$ & & $\mu \mathrm{m}$ & $\mathrm{m}^{2} \mathrm{~m}^{-3}$ & $----\mathrm{m}$ & -- & \\
\hline 35 & 23 & 0.94 & 2.6 & 850 & $5.1 \times 10^{-8}$ & $1.1 \times 10^{-7}$ & 0.45 \\
\hline 47 & 48 & 0.83 & 3.8 & 144 & $2.6 \times 10^{-8}$ & $4.6 \times 10^{-8}$ & 0.57 \\
\hline 79 & 33 & 0.69 & 3.2 & 396 & $4.1 \times 10^{-8}$ & $2.3 \times 10^{-7}$ & 0.18 \\
\hline 179 & 32 & 0.98 & 3.1 & 334 & $3.4 \times 10^{-8}$ & $5.4 \times 10^{-7}$ & 0.06 \\
\hline 208 & 56 & 0.91 & 4.2 & 337 & $7.9 \times 10^{-8}$ & $7.9 \times 10^{-7}$ & 0.1 \\
\hline 212 & 31 & 0.95 & 3.1 & 261 & $2.5 \times 10^{-8}$ & $1.1 \times 10^{-6}$ & 0.02 \\
\hline 257 & 29 & 0.83 & 3.0 & 335 & $2.9 \times 10^{-8}$ & $7.4 \times 10^{-7}$ & 0.04 \\
\hline 486 & 34 & 0.98 & 3.2 & 419 & $4.6 \times 10^{-8}$ & $4.3 \times 10^{-7}$ & 0.11 \\
\hline 501 & 73 & 0.99 & 4.7 & 138 & $4.7 \times 10^{-8}$ & $8.5 \times 10^{-8}$ & 0.55 \\
\hline 511 & 27 & 0.95 & 2.9 & 311 & $2.6 \times 10^{-8}$ & $1.7 \times 10^{-7}$ & 0.15 \\
\hline 521 & 32 & 0.99 & 3.1 & 258 & $2.5 \times 10^{-8}$ & $9.4 \times 10^{-8}$ & 0.27 \\
\hline 525 & 42 & 0.88 & 3.6 & 83 & $1.3 \times 10^{-8}$ & $6.9 \times 10^{-8}$ & 0.18 \\
\hline Mean & 37.9 & & 3.4 & 322.2 & $3.7 \times 10^{-8}$ & $4.3 \times 10^{-7}$ & \\
\hline SD & 14.1 & & 0.57 & 188.1 & $1.7 \times 10^{-8}$ & $4.5 \times 10^{-7}$ & \\
\hline $\mathrm{CV}$ & 0.37 & & 0.17 & 0.58 & 0.45 & 1.05 & \\
\hline
\end{tabular}

\section{Rewetting after Prolonged Drought}

Prolonged drainage flow of $<10^{-9} \mathrm{~m} \mathrm{~s}^{-1}$ is used here to define the hydrological drought. Thus, it lasted 197 d from 27 June 2015 to 10 Jan. 2016, i.e., from Days 270 to 467 (Day 1 is set at 1 Oct. 2014). The lysimeter's minimum weight was down to $3008 \mathrm{~kg}$

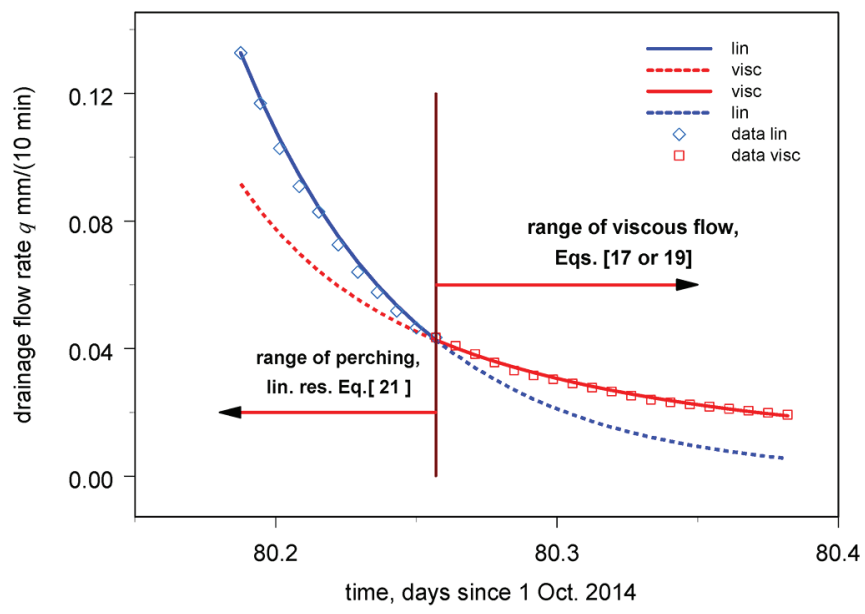

Fig. 7. Analysis of drainage flow at Day 80 after 1 Oct. 2014. Solid blue line "lin" and blue diamonds indicate a section of a time series following drainage of a linear reservoir, Eq. [22]; solid red line "visc" and red boxes indicate a section of a time series following viscous flow theory, Eq. [18] or [20]; dashed lines show extensions into the other sections. Optimization is by shifting the crossover point of the two approaches to the maximum of the two $r^{2}$ values. Table 5 lists the relevant parameters. shortly before the onset of drainage at Day 467. Drainage flow started anew with a surge of $2.7 \times 10^{-7} \mathrm{~m} \mathrm{~s}^{-1}$ while the lysimeter weight meanwhile increased to $3142 \mathrm{~kg}$. The three panels in Fig. 8 illustrate from top to bottom nine precipitation periods, 1 to 9 , the corresponding characteristics of nine wetting and draining fronts, and drainage flow during rewetting. Table 7 lists the nine WCWs' constant wetting front velocities $v$. They follow from the slope of the linear regression of FDR depths vs. times of first $\theta$ increase at the respective depths as demonstrated for Day 511 (Fig. 5 and 6). The beginning of a precipitation period indicates a WCW's release at the surface. The pluses in Table 7 indicate the depths involved in computing $v$. The duration of a precipitation period $\left(T_{\mathrm{E}}-T_{\mathrm{B}}\right)$ and $v$ of the corresponding WCW determine $T_{\mathrm{I}}$ and $Z_{\mathrm{I}}$ of front interception (Eq. [6-7]). After interception, a wetting front moves according to Eq. [12]. For practical reasons, the detailed presentation of the characteristics are limited here to the range from the surface to the quartz-sand interface at the $1.35-\mathrm{m}$ depth and to the end of Day 469. The wetting fronts of WCWs 1, 4, and 5 got stuck before arriving at the $1.35-\mathrm{m}$ depth. The fronts of the other WCWs arrived there, but the $Z_{\mathrm{I}}$ of WCWs 2, 3, and 6 were above the interface. Thus, not only the amount of precipitation leading to a WCW determines its penetration depth but antecedent $\theta$ also needs to be considered as the comparison of WCW 3 with WCW 7 (Table 7) reveals.

First drainage flow appears as a surge. Its steep increase is presumably associated with early perching of water between the $0.9-\mathrm{m}$ 
Table 5. The reservoir constant $(\lambda), r^{2}$ results from Eq. [16] and [21], the maximum rate of drainage flow $\left(q_{\mathrm{d} \text { max }}\right)$ and the maximum volume flux density of viscous flow $\left(q_{\text {visc,max }}\right)$, and the duration of perching for periods undergoing perching with presumed positive pressure on drainage (Eq. [21]).

\begin{tabular}{|c|c|c|c|c|c|c|}
\hline \multirow[b]{2}{*}{ Day† } & \multirow[b]{2}{*}{$\lambda$} & \multicolumn{2}{|l|}{$r^{2}$} & \multirow[b]{2}{*}{$q_{\mathrm{d}, \max }$} & \multirow[b]{2}{*}{$q_{\text {visc, } \max }$} & \multirow{2}{*}{$\begin{array}{l}\text { Perching } \\
\text { duration }\end{array}$} \\
\hline & & (Eq. [16]) & (Eq. [21]) & & & \\
\hline & \multicolumn{3}{|l|}{$s^{-1}$} & \multicolumn{2}{|c|}{$\longrightarrow \mathrm{m} \mathrm{s}^{-1}$} & $\mathrm{~h}: \min$ \\
\hline 47 & -2.98 & 0.98 & 0.99 & $4.6 \times 10^{-8}$ & $3.8 \times 10^{-8}$ & $6: 20$ \\
\hline $79-80 \neq$ & -6.34 & 0.99 & 0.99 & $2.3 \times 10^{-7}$ & $7.2 \times 10^{-8}$ & $4: 10$ \\
\hline 87 & -5.25 & 0.97 & 0.99 & $4.6 \times 10^{-7}$ & $2.1 \times 10^{-7}$ & $7: 10$ \\
\hline 179 & -8.77 & 0.97 & 0.94 & $5.4 \times 10^{-7}$ & $1.1 \times 10^{-7}$ & $13: 40$ \\
\hline 212 & -4.37 & 0.99 & 0.98 & $1.1 \times 10^{-6}$ & $3.9 \times 10^{-7}$ & $8: 10$ \\
\hline 257 & -7.86 & 0.98 & 0.99 & $7.4 \times 10^{-7}$ & $3.4 \times 10^{-7}$ & $4: 20$ \\
\hline 466 & -2.40 & 0.94 & 0.88 & $2.7 \times 10^{-7}$ & $8.7 \times 10^{-8}$ & $9: 35$ \\
\hline 469 & -2.11 & 0.99 & 0.99 & $8.8 \times 10^{-8}$ & $7.9 \times 10^{-8}$ & $3: 50$ \\
\hline 486 & -2.15 & 0.88 & 0.98 & $4.3 \times 10^{-7}$ & $2.0 \times 10^{-7}$ & $1: 40$ \\
\hline 501 & -4.85 & 0.85 & 0.98 & $8.5 \times 10^{-8}$ & $7.7 \times 10^{-8}$ & $4: 50$ \\
\hline 521 & -2.90 & 0.97 & 0.97 & $9.4 \times 10^{-8}$ & $7.7 \times 10^{-8}$ & $7: 10$ \\
\hline
\end{tabular}

Table 6. Perching thresholds and related time fractions of perching.

\begin{tabular}{lll}
$\begin{array}{l}\text { Perching } \\
\text { threshold }\end{array}$ & $\begin{array}{l}\text { 10-min periods } \\
\text { exceeding threshold }\end{array}$ & $\begin{array}{l}\text { Time fraction of drainage } \\
\text { flow during } 577-d \text { period }\end{array}$ \\
$\mathrm{m} \mathrm{s}^{-1}$ & no. & \\
$5 \times 10^{-8}$ & 4483 & 0.092 \\
$10^{-7}$ & 1687 & 0.035 \\
$2 \times 10^{-7}$ & 771 & 0.0158 \\
$5 \times 10^{-7}$ & 224 & 0.005 \\
$10^{-6}$ & 11 & 0.0002 \\
\hline
\end{tabular}

depth and the outlet at the 1.5-m depth that initiates a sudden breakthrough after sufficient pressure buildup. First drainage occurred under positive pressure, lasting $3 \mathrm{~h} 50 \mathrm{~min}$ as Table 5 notes for Day 469. Table 8 lists sequentially the features leading to first drainage and perching. The lysimeter's early weight increase is due to precipitation, while the start of drainage occurs at the weight maximum. Perching and the peak of drainage are associated with decreasing weight. Among others, these features may explain the surge-type drainage initiation after the prolonged drought.

\section{Discussion}

Table 4 compares the rate of preferential flow at the 0.9 -m depth, $q_{0.9}$, with the maximum rate of observed drainage flow, $q_{\mathrm{d} \text {,max }}$, from the same episode. The ratios of $q_{0.9} / q_{\mathrm{d} \text {, max }}$ are in the range from 0.02 to 0.57 , thus the rate of viscous flow was in all cases

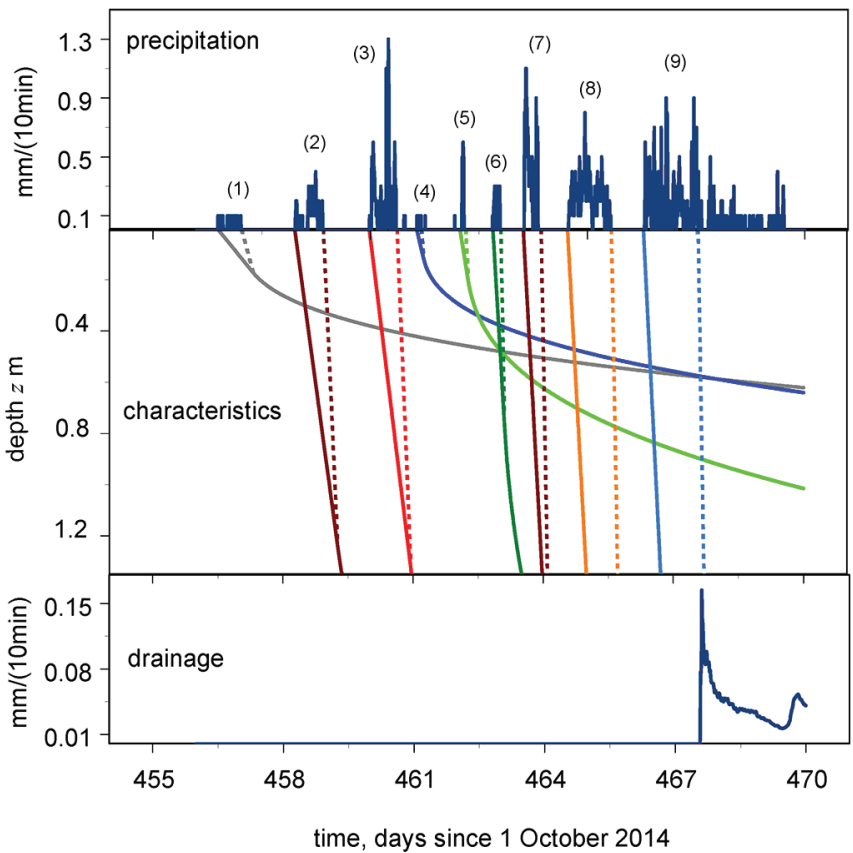

Fig. 8. Wetting and draining front characteristics during rewetting of the lysimeter soil after the prolonged drought: precipitation episodes 1 to 9 (top); characteristics of the nine water content waves (WCWs) that the precipitation episodes initiated, with solid lines indicating the wetting fronts and dashed lines the draining fronts (the characteristics were terminated at the $1.35-\mathrm{m}$ depth, i.e., at the interface between the soil and quartz filling; WCWs 1,4 , and 5 did not reach the $1.35-\mathrm{m}$ depth before Day 470, while the depth at which the wetting front intercepted the draining front $Z_{\mathrm{I}}$ was $<1.35 \mathrm{~m}$ for WCWs 2, 3, and 6) (center); and initiation of drainage after prolonged drought (bottom). Table 7 compiles the parameters of the nine WCWs (see also Fig. 1).

inferior to the rate of drainage. There are at least two explanations for maximum drainage flow markedly exceeding preferential flow: (i) spatial variability may envelop preferential flows with higher rates than those captured with the FDR probes; or (ii) preferential flow may trigger capillary flow at some depths that would lead to "pushing out old water." Distinction of the two explanations requires an expansion of the protocol, for instance by including studies with pulses of conservative tracers.

Viscous flow provides for the separation of exclusively gravity-driven drainage, i.e., viscous flow, from drainage that is additionally driven by pressure gradients, i.e., linear-reservoir flow. The former flow is related to presumably sufficient aeration, while during the latter flow, blocking of sufficient gas exchange with the atmosphere is likely. However, under the auspice of the spatial variability, there might be considerable soil volumes not being aerated even under the regime of free drainage. Thus, independent checks on anoxia would strengthen the assessments.

The product of mobile water content $w$ and wetting front velocity $v$ results in the volume flux density $q$ at the wetting front (Eq. [4]), whereas $w$ is deduced from the difference between the water contents prior to and after the passing of the wetting front, 
Table 7. Properties of nine water content waves (WCWs) during rewetting up to Day 467 (10 Jan. 2016) with wetting front velocity $v$, film thickness at the 0.9 -m depth $F_{0.9}$, specific contact area at the 0.9 -m depth $L_{0.9}$, depth of front interception $Z_{\mathrm{I}}$, volume flux density of viscous flow at the 0.9 -m depth $q_{0.9}$, and total precipitation during the interval leading to the WCW, $\Sigma N$.

\begin{tabular}{|c|c|c|c|c|c|c|c|c|c|c|c|}
\hline \multirow[b]{2}{*}{ WCW } & \multirow[b]{2}{*}{$v$} & \multicolumn{5}{|c|}{ Depths used in $v$ regression $\dagger$} & \multirow[b]{2}{*}{$F_{0.9}$} & \multirow[b]{2}{*}{$L_{0.9}$} & \multirow[b]{2}{*}{$Z_{\mathrm{I}}$} & \multirow[b]{2}{*}{$q_{0.9}$} & \multirow[b]{2}{*}{$\Sigma N$} \\
\hline & & $0.1 \mathrm{~m}$ & $0.3 \mathrm{~m}$ & $0.6 \mathrm{~m}$ & $0.9 \mathrm{~m}$ & $r^{2}$ & & & & & \\
\hline & $\times 10^{-6} \mathrm{~m} \mathrm{~s}^{-1}$ & & & & & & $\mu \mathrm{m}$ & $\mathrm{m}^{2} \mathrm{~m}^{-3}$ & $\mathrm{~m}$ & $\mathrm{~m} \mathrm{~s}^{-1}$ & $\mathrm{~mm}$ \\
\hline 1 & 2.4 & + & & & & - & 0.9 & - & 0.17 & - & 1.9 \\
\hline 2 & 14.5 & + & + & & & 0.96 & 2.1 & 1760 & 1.24 & $5.4 \times 10^{-8}$ & 9.8 \\
\hline 3 & 16.0 & + & + & + & & 0.99 & 2.2 & 904 & 1.33 & $3.2 \times 10^{-8}$ & 17.8 \\
\hline 4 & 8.3 & + & & & & - & 1.6 & - & 0.12 & - & 0.8 \\
\hline 5 & 12.2 & + & + & & & 0.89 & 1.9 & - & 0.21 & - & 2.3 \\
\hline 6 & 33.1 & + & + & & & 0.98 & 3.2 & 629 & 0.77 & $6.6 \times 10^{-8}$ & 3.5 \\
\hline 7 & 35.6 & + & + & & + & 0.99 & 3.2 & 959 & 1.89 & $1.0 \times 10^{-7}$ & 19.5 \\
\hline 8 & 35.9 & + & + & + & + & 0.98 & 3.3 & 2688 & 4.69 & $3.2 \times 10^{-7}$ & 32.6 \\
\hline 9 & 35.9 & + & + & + & + & 0.92 & 3.3 & 362 & 6.39 & $4.3 \times 10^{-8}$ & 35.2 \\
\hline
\end{tabular}

$\theta_{\text {ante }}$ and $\theta_{\max }$ (Fig. 5). The specific contact area $L$ then follows from Eq. [2]. It represents the locus of exchanges between the mobile water of the WCW and the sessile parts of the permeable medium consisting of solid, liquid, and gas phases. Exchange processes include heat, solutes, particles, and water. The latter is subject to capillarity exerted from unsaturated, sessile, and porous parts of a permeable medium onto the mobile water as the film glides by. These kinds of exchange processes might be fast in view of the miniscule thicknesses of the films of $10 \mu \mathrm{m}$ or less, and they might be distinctly different from the diffusion-type exchange processes at the Darcy scale (see, for instance, Šimůnek and van Genuchten, 2008).

The parameters $F$ and $L$ are now set in a broader context. Hincapié and Germann (2009) provided frequency distributions of the two parameters from $215 \theta(z, t)$ time series that were recorded in situ as well as in columns of undisturbed soils. They reported 10, 50, and $90 \%$ of the $F$ distribution at about 10,15 , and $30 \mu \mathrm{m}$, and of the $L$ distribution at 1000,2500 , and $6000 \mathrm{~m}^{2} \mathrm{~m}^{-3}$, respectively. Both $F$ and $L$ found in the lysimeter soil (Tables 4 and 7 ) score at the

Table 8 . Water balance elements shortly before and after the first drainage at the end of a prolonged drought. Time $t=0$ was set at the minimum weight at Day 468, 22 h, 19 min.

\begin{tabular}{|llll|}
\hline Time & Drainage property & Weight & Weight property \\
\hline h:min & & $\mathrm{kg}$ & \\
0 & 0 & 0 & minimum \\
14:24 & 0 & 5.1 & maximum \\
$15: 36$ & start & 5.1 & maximum \\
18:58 & begin perching & 4.2 & decreasing \\
21:36 & peak flow & 3.3 & decreasing \\
22:48 & end perching & 2.8 & decreasing \\
$39: 36$ & end drainage & -0.5 & \\
\hline
\end{tabular}

lower ends of the respective frequency distributions. Germann and Karlen (2016) applied the viscous flow approach to infiltration in a sandy-loamy Cambisol that was similar to the soil reported here. Their mean $F$ of $4.2 \mu \mathrm{m}$ from 16 measurements is close to the mean $F$ of $3.4 \mu \mathrm{m}$ as listed in Table 4 .

Wetting front velocity is an unambiguous parameter for comparison across systems and processes of preferential flow. On the one hand, Dubois (1991) applied uranine and eosine tracers about $1800 \mathrm{~m}$ of vertical height above the Mont Blanc car tunnel that connects France with Italy. Seepage in the tunnel was at atmospheric pressure, indicating that viscosity completely consumed the energy supplied by gravity. He found the tracers within $108 \mathrm{~d}$ in seeps in the tunnel, yielding a front velocity of about $1.9 \times 10^{-4} \mathrm{~m} \mathrm{~s}^{-1}$. Thus, the front velocity across granite exceeds by a factor of five the mean velocity listed in Table 4. On the other hand, Germann (2014) reported water balance calculations with the viscous flow approach at the millimeter scale. Infiltration was in sand boxes, while neutron radiography recorded water content variations (Hincapié and Germann, 2010). The corresponding wetting front velocity was $4 \times 10^{-4} \mathrm{~m}$ $\mathrm{s}^{-1}$. The $v$ values reported in Table 4 in the range of $4 \times 10^{-5} \mathrm{~m}$ $\mathrm{s}^{-1}$ are about an order of magnitude inferior to those mentioned above. Nevertheless, the relatively narrow range of $v$ with respect to the vast variation of lengths of the respective permeable media raises hope that issues of dimensions of representative elementary volumes and scales are by far more relaxed in viscous flow than in capillary flow.

Nine episodes of precipitation routing prior to first drainage illustrate rewetting of the soil based on the propagation of WCWs. However, some analyses are less convincing, as WCWs 1 and 4 in Table 7 demonstrate those cases in which only the onset of 
precipitation and $\theta$ increase at the $0.1-\mathrm{m}$ depth are available for determining $v$. Thus, procedures and results leading to Fig. 8 offer a blueprint outlining the potential of viscous flow, while more detailed modeling of preferential infiltration and drainage is required that has to include the definition of objective functions and testing model performance against them. Germann (2014) demonstrated the complete congruence of viscous flow with kinematic wave theory according to Lighthill and Witham (1955) under the prerequisite of fixing to 3 the exponent in the flow equation, Eq. [3]. Viscous flow is a hydromechanical approach to preferential flow, whereas the kinematic wave theory provides the mathematical tool for dealing with it, including the rules of superposition when faster WCWs catch up with slower ones from previous releases. Thus, in the case of our lysimeter, each 10-min interval of water input to the surface becomes computationally tractable by simply requiring its specific $F$ and $L$ parameters. Given the wealth of lysimeter data, there is confidence that empirical relationships are deducible between $F$ and $L$ on the one side and $P$ and $\theta_{\text {ante }}$ on the other side. For instance, Table 4 shows that the $\mathrm{CV}$ of $F$ is about one-third that of $L$, pointing toward a more narrowly defined variation of flow path widths compared with a wider variation of the specific surface areas that evolved under the auspice of $P$ and $\theta_{\text {ante }}$

Viscous flow applies to the three categories of preferential infiltration, i.e., finger flow, macropore flow, and nonequilibrium flow at the Darcy scale. As demonstrated, viscous flow relies on the wetting front velocity, therefore it is a priori suited to cope with rapid flow components. This is in contrast to Richards (1931) capillary flow and its HYDRUS-2D (Šimůnek et al., 1999) approach that does not always catch the wetting front velocities, as Germann and Hensel (2006) demonstrated. However, viscous flow definitively does not apply to capillary rise where the gradients of gravity and capillarity act in opposite directions.

\section{Conclusion}

Preferential flow is fast, occurs mainly during infiltration, and only minor parts of the soil volume participate in it. Viscous flow theory combines velocity, the volume fraction of mobile water, and volume flux density, yielding a protocol that applies well to the study of preferential flow in the soil of a weighing and freely draining lysimeter. The simple procedure of estimating the thickness and the specific surface area of the moving water film is outlined. Similar protocols and procedures apply to preferential flow in situ. Thus, viscous flow approaches are suited to compare at the Darcy-scale preferential flows in the soils in situ and in the analogs of the corresponding lysimeters. There are weak requirements concerning dimensions of elementary volumes representing viscous flow, and the approach is scale robust, as the tracer experiment in the Mont Blanc granite of Dubois (1991) suggests. Therefore, viscous flow protocols and procedures may also apply to preferential flow in the vadose zone from the surface to unconfined groundwater tables.
Kinematic wave theory according to Lighthill and Witham (1955) provides the mathematical tool for modeling viscous flow in time steps comparable to those of data recording. The wealth of lysimeter data just longs for such modeling endeavors.

\section{Acknowledgments}

The comments and suggestions expressed by three reviewers and the associate editor greatly helped to hone the manuscript.

\section{References}

Abdou, H.M., and M. Flury. 2004. Simulation of water flow and solute transport in free-drainage lysimeters and field soils with heterogeneous structures. Eur. J. Soil Sci. 55:229-241. doi:10.1046/j.1365-2389.2004.00592.x

al Hagrey, S.A., T. Schubert-Klempnaver, D. Wachsmuth, J. Michaelsen, and R. Meissner. 1999. Preferential flow: First results of a full-scale flow model. Geophys. J. Int. 138:643-654. doi:10.1046/j.1365-246x.1999.00906.x

Atkinson, T.C., and D.I. Smith. 1974. Rapid groundwater flow in fissures in the Chalk: An example from South Hampshire. Q. J. Eng. Geol. 7:197205. doi:10.1144/GSL.QJEG.1974.007.02.05

Beven, K.J., and P.F. Germann. 1982. Macropores and water flow in soils. Water Resour. Res. 18:1311-1325. doi:10.1029/WR018i005p01311

Darcy, H. 1856. Les fontaines publiques de la ville de Dijon. Dalmont, Paris.

Dubois, J.-D. 1991. Typologie des aquifers du cristallin: Exemples des massifs des Aiguilles Rouges et du Mont-Blanc. (Typology of aquifers in the cristaline: Examples from the massifs Aguilles Rouges and Mt. Blanc). Ph.D. diss. 950. Dep. of Civil Engineering, EPFL, Lausanne, Switzerland.

Gebler, S., H.-J. Hendricks-Franssen, T. Pütz, H. Post, M. Schmidt, and H. Vereecken. 2015. Actual evapotranspiration and precipitation measured by lysimeters: A comparison with eddy covariance and tipping bucket. Hydrol. Earth Syst. Sci. 19:2145-2161. doi:10.5194/hess-19-2145-2015

Germann, P.F. 1986. Rapid drainage response to precipitation. Hydrol. Processes 1:3-13. doi:10.1002/hyp.3360010103

Germann, P.F. 2014. Preferential flow: Stokes approach to infiltration and drainage. Geographica Bernensia, Bern, Switzerland.

Germann, P.F., and S.A. al Hagrey. 2008. Gravity-driven and viscositydominated infiltration in a full-scale sand model. Vadose Zone J. 7:1160-1169. doi:10.2136/vzj2007.0172

Germann, P.F., and D. Hensel. 2006. Poiseuille flow inferred from velocities of wetting fronts in soils. Vadose Zone J. 5:867-876. doi:10.2136/vzj2005.0080

Germann, P.F., and M. Karlen. 2016. Viscous-flow approach to in situ infiltration and in vitro hydraulic conductivity determination. Vadose Zone J. 15(2). doi:10.2136/vzj2015.05.0065

Hagenau, J., R. Meissner, and H. Borg. 2015. Effect of exposure on the water balance of two identical lysimeters. J. Hydrol. 520:69-74 doi:10.1016/j.jhydrol.2014.11.030

Harrold, L.L., and F.R. Dreibelbis. 1958. Evaluation of agricultural hydrology by monolith lysimeters. USDA Tech. Bull. 1179. US Gov. Print. Office Washington, DC.

Hincapié, I.A., and P. Germann. 2009. Abstraction from infiltrating water content waves during weak viscous flows. Vadose Zone J. 8:996-1003. doi:10.2136/vzj2009.0012

Hincapié, I.A., and P. Germann. 2010. Water content wave approach applied to neutron radiographs of finger flow. Vadose Zone J. 9:278-284. doi:10.2136/vzj2009.0102

Jarvis, N., J. Koestel, and M. Larsbo. 2016. Understanding preferential flow in the vadose zone: Recent advances and future prospects. Vadose Zone J. 15(12). doi:10.2136/vzj2016.09.0075

Kelley, G.P., W.M. Edwards, L.L. Harrold, and J.L. McGuiness. 1975. Soils of the North Appalachian Watershed. USDA Misc. Publ. 1296. US Gov. Print. Office, Washington, DC.

Lawes, J.B., J.H. Gilbert, and R. Warington. 1882. On the amount and composition of the rain and drainage water collected at Rothamsted. Williams, Clowes and Sons, London.

Lighthill, M.J., and G.B. Witham. 1955. On kinematic waves: I. Flood movement in long rivers. Proc. R. Soc. London Ser. A 229:281-316. doi:10.1098/rspa.1955.0088

Meissner, R., M.N.V. Prasad, G. Du Laing, and J. Rinklebe. 2010. Lysimeter application for measuring the water and solute fluxes with high precision. Curr. Sci. 99:601-607. 
Meissner, R., H. Rupp, and M. Seyfarth. 2008. Advances in outdoor lysimeter techniques. Water Air Soil Pollut. Focus 8:217-225. doi:10.1007/s1 1267-007-9166-2

Prasuhn, V., C. Humphrys, and E. Spiess. 2016. Seventy-two lysimeters for measuring water flows and nitrate leaching under arable land. In: NAS International Workshop on Applying the Lysimeter Systems to Water and Nutrient Dynamics. Natl. Inst. of Agric. Sci., Wanju, Ko rea. p. 123-146.

Prasuhn, V., E. Spiess, and M. Seyfarth. 2009. Die neue Lysimeteranlage Zürich-Reckenholz. In: Bericht 13: Gumpensteiner Lysimetertagung, Irdning, Austria. 21-22 Apr. 2009. Lehr- und Forschungszentrum für Landwirtschaft Raumberg-Gumpenstein, Irdning, Austria. p. 11-16.

Reeves, M.J. 1979. Recharge and pollution of the English Chalk: Some possible mechanisms. Eng. Geol. 14:231-240. doi:10.1016/0013-7952(79)90065-6

Richards, L.A. 1931. Capillary conduction of liquids through porous mediums. Physics 1:318-333. doi:10.1063/1.1745010
Schuhmann, A., O. Gans, S. Weiss, J. Frank, G. Klammler, G. Haberhau er, and M.H. Gerzabek. 2016. A long-term lysimeter experiment to investigate the environment dispersion of the herbicide chloridazon and its metabolites: Comparison of lysimeter types. J. Soils Sediments 16:1032-1045. doi:10.1007/s11368-015-1311-3

Selker, J., J.-Y. Parlange, and T. Steenhuis. 1992. Fingered flow in two dimensions: 2. Predicting finger moisture profile. Water Resour. Res. 28:2523-2528. doi:10.1029/92WR00962

Šimůnek, J., M. Šenja, and M.Th. van Genuchten. 1999. HYDRUS-2D: Simu lating water flow, heat and solute transport in two-dimensional variably saturated media. Version 2.0. US Salinity Lab., Riverside, CA.

Šimůnek, J., and M.Th. van Genuchten. 2008. Modeling nonequilibrium flow and transport processes using HYDRUS. Vadose Zone J. 7:782-797. doi:10.2136/vzj2007.0074

Sturzenegger, L. 2010. Data preparation and evaluation of the lysimeter station Reckenholz: Evapotranspiration modeling. M.Sc. thesis. ETH, Zürich. 